\title{
COMPARATIVE TOXICITY EVALUATION OF TARGETED ANTICANCER THERAPEUTICS IN EMBRYONIC ZEBRAFISH AND SEA URCHIN MODELS
}

\author{
Tamara Babic, ${ }^{1}$ Jelena Dinic, ${ }^{2}$ Sonja Stojkovic Buric, ${ }^{2}$ Stefan Hadzic, ${ }^{2}$ \\ Milica Pesic, ${ }^{2}$ Dragica Radojkovic ${ }^{1}$ and Aleksandra Divac Rankov ${ }^{1, *}$ \\ ${ }^{1}$ Institute of Molecular Genetics and Genetic Engineering, University of Belgrade, \\ Vojvode Stepe 444a, 11010, Belgrade, Serbia \\ 2Institute for Biological Research "Sinisa Stankovic", Department of Neurobiology, \\ University of Belgrade, Despota Stefana 142, 11060, Belgrade, Serbia
}

(Received: April 23, 2018; accepted: July 30, 2018)

\begin{abstract}
Cancer drug resistance and poor selectivity towards cancer cells demand the constant search for new therapeutics. PI3K-Akt-mTOR and RAS-MAPK-ERK signaling pathways are key mechanisms involved in cell survival, proliferation, differentiation, and metabolism and their deregulation in cancer can promote development of therapy resistance. We investigated the effects of targeted inhibitors (wortmannin, GSK690693, AZD2014 and tipifarnib) towards these two pathways on early zebrafish and sea urchin development to assess their toxicity in normal, fast proliferating cells. PI3K inhibitor wortmannin and RAS inhibitor tipifarnib displayed highest toxicity while GSK690693, a pan-Akt kinase inhibitor, exhibited a less significant impact on embryo survival and development. Moreover, inhibition of the upstream part of the PI3K-Akt-mTOR pathway (wortmannin/GSK690693 co-treatment) produced a synergistic effect and impacted zebrafish embryo survival and development at much lower concentrations. Dual mTORC1/mTORC2 inhibitor AZD2014 showed no considerable effects on embryonic cells of zebrafish in concentrations substantially toxic in cancer cells. AZD2014 also caused the least prominent effects on sea urchin embryo development compared to other inhibitors. Significant toxicity of AZD2014 in human cancer cells, its capacity to sensitize resistant cancers, lower antiproliferative activity against human normal cell lines and fast proliferating embryonic cells could make this agent a promising candidate for anticancer therapy.
\end{abstract}

Keywords: PI3K-Akt-mTOR signaling pathway - RAS-MAPK-ERK signaling pathway - zebrafish (Danio rerio) - sea urchin (Arbacia lixula) - AZD2014

\section{INTRODUCTION}

One of the main obstacles for successful cancer treatment is the development of resistance to chemotherapy. PI3K-Akt-mTOR and RAS-MAPK-ERK signaling pathways are among the main cellular mechanisms involved in the regulation of cell survival, proliferation, differentiation, and metabolism [24, 26]. Deregulation of these pathways may result in resistance to therapy which is common for numerous cancer types [23, 24]. The role of PI3K-Akt-mTOR and RAS-MAPK-ERK pathway inhibition in chemosensitization of resistant cancers has been extensively studied and vari-

\footnotetext{
*Corresponding author, e-mail: aleksandradivac@imgge.bg.ac.rs
} 
ous inhibitors of these pathways were investigated as potential agents to overcome the problem of multidrug resistance [1, 27, 29]. Additional problem in cancer therapy is its nondiscriminatory nature between normal and cancer cells. Many agents do not spare normal cells and may have substantial cytotoxic effects on normal tissue. Some cell types in bone marrow or gastrointestinal lining have a rapid turnover, and can be more susceptible to drug toxicity. For instance, the toxic effect in bone marrow cells can lead to development of anemia and neutropenia, while toxicity in the gastrointestinal tract can result in colitis [5].

Zebrafish represents an excellent model to study the toxicity of different substances [12]. As an in vivo system for toxicology, zebrafish has many advantages including rapid and ex utero development, transparent and small embryos in early stages, high fecundity enabling high-throughput screening and cost effectiveness [4]. Zebrafish genome has approximately $70 \%$ of human genes and about $82 \%$ of potential human disease related genes have at least one zebrafish orthologue [16]. Additionally, the studies of known toxic substances on zebrafish revealed $63-100 \%$ of predictability which makes zebrafish a good model to study toxic effects [11, 14, 17].

The sea urchin embryo has long been used as a model for developmental studies and drug toxicity testing. Multiple factors such as inexpensive growth procedure, simple artificial spawning and fertilization, rapid synchronous development, optical transparency of embryos and well understood embryogenesis, make this organism suitable for conducting a variety of biological tests. Other advantages that make sea urchin embryo particularly convenient for toxicity studies include high permeability of eggs and embryos to chemicals, rapid cell divisions, observable markers of viability and biochemical similarity to vertebrates and mammals [28]. As a result, various antiproliferative agents have been tested for their effects on the sea urchin embryo development $[20,30]$.

The aim of this study was to assess the effect of different signaling pathway inhibitors in vertebrate and invertebrate embryonic models. For this reason, we followed early zebrafish (Danio rerio) and sea urchin (Arbacia lixula) development in order to assess inhibitors' toxicity on normal, fast proliferating cells. We have investigated four inhibitors of key components in PI3K-Akt-mTOR and RAS-MAPK-ERK pathways: wortmannin - specific inhibitor of PI3K; GSK690693 - ATP-competitive Akt kinase inhibitor, AZD2014 - dual mTORC1 and mTORC2 inhibitor and tipifarnib - RAS inhibitor.

\section{MATERIALS AND METHODS}

\section{Drugs}

Wortmannin, GSK690693, AZD2014, and tipifarnib were kindly provided by Selleckchem (Houston, TX, USA). All drugs were diluted in DMSO and $10 \mathrm{mM}$ aliquots were stored at $-20^{\circ} \mathrm{C}$. Before treatment, all drugs were freshly diluted in water. 


\section{Zebrafish husbandry}

Tübingen wild type zebrafish (Danio rerio) were housed at $28 \pm 1{ }^{\circ} \mathrm{C}$ on a $12: 12$ light-dark photoperiod, according to good laboratory practice. Adults and embryos were maintained in water containing $5.5 \mathrm{mg} \mathrm{KCl}, 294 \mathrm{mg} \mathrm{CaCl} \cdot 2 \mathrm{H}_{2} \mathrm{O}, 123 \mathrm{mg}$ $\mathrm{MgSO}_{4} \cdot 7 \mathrm{H}_{2} \mathrm{O}$ and $63 \mathrm{mg} \mathrm{NaHCO} 3$ per L. Zebrafish were spawned every seven days. Spawn was discarded if more than $10 \%$ of eggs were unfertilized.

\section{Zebrafish treatments}

Experiments were performed in 24-well plates. Twelve embryos were placed in each well in $750 \mu \mathrm{l}$ of the appropriate solution. Three different concentrations of each inhibitor were tested per each experiment (wortmannin: $0.5 \mu \mathrm{M}, 1 \mu \mathrm{M}, 2.5 \mu \mathrm{M}$; GSK690693: $0.5 \mu \mathrm{M}, 1 \mu \mathrm{M}, 5 \mu \mathrm{M}$; AZD2014: $0.1 \mu \mathrm{M}, 0.5 \mu \mathrm{M}, 1 \mu \mathrm{M}$, tipifarnib: $1 \mu \mathrm{M}, 5 \mu \mathrm{M}, 10 \mu \mathrm{M})$. Two different combinations of inhibitors were also tested: $1 \mu \mathrm{M}$ wortmannin $+1 \mu \mathrm{M}$ GSK690693 and $1 \mu \mathrm{M}$ GSK690693 $+1 \mu \mathrm{M}$ AZD2014. Treatments started 2, 6 or 24 hours post fertilization (hpf) for single treatments and $6 \mathrm{hpf}$ for combination treatments. Treatments for all concentrations were repeated three times using embryos obtained from three independent spawns. All experiments contained untreated and $0.01 \%$ dimethyl sulfoxide (DMSO) treated groups, as controls.

\section{Developmental toxicity screen}

The embryos were observed under the stereomicroscope PXS- IV (Optica Co. Ltd, Thailand) at 40x magnification and imaged with camera CKX41 (Olympus, Japan). Embryo survival was observed at 24, 48 and $72 \mathrm{hpf}$. Embryos that were coagulated or where no heartbeat could be detected were considered dead. Embryo hatching rate was observed at 48 and $72 \mathrm{hpf}$, as hatching normally occurs between 48 and $72 \mathrm{hpf}$. Developmental malformations (head malformation, eye malformation, eye pigmentation, otoliths malformation, chorda malformation, tail malformation, scoliosis, yolk deformation/edema, heart malformation, pericardial edema, tail circulation, growth retardation, body pigmentation) were observed at $72 \mathrm{hpf}$ after hatching.

\section{Handling of sea urchin gametes}

Adult Arbacia lixula sea urchins were collected by scuba in the Adriatic Sea and were immediately transported (maximum $1 \mathrm{~h}$ transportation time) to the Institute for Marine Biology (Kotor, Montenegro). They were subsequently kept in circulating and filtered artificial sea water (ASW) $\left(27.6 \mathrm{~g} / 1 \mathrm{NaCl}, 0.67 \mathrm{~g} / 1 \mathrm{KCl}, 1.36 \mathrm{~g} / 1 \mathrm{CaCl}_{2} \times\right.$ $\left.2 \mathrm{H}_{2} \mathrm{O}, 6.29 \mathrm{~g} / 1 \mathrm{MgSO}_{4} \times 7 \mathrm{H}_{2} \mathrm{O}, 4.66 \mathrm{~g} / \mathrm{l} \mathrm{MgCl}_{2} \times 6 \mathrm{H}_{2} \mathrm{O}, 0.18 \mathrm{~g} / 1 \mathrm{NaHCO}_{3}, \mathrm{pH} 7.5\right)$ at 
$21{ }^{\circ} \mathrm{C}$. Eggs or sperm were obtained by injecting the animals with $1 \mathrm{ml}$ of $0.55 \mathrm{M}$ $\mathrm{KCl}$, and fertilization of the eggs was carried out using the sperm of one male with eggs acquired from 2 to 4 females.

\section{Sea urchin embryo treatments}

Approximately 100 fertilized sea urchin eggs were placed in $1 \mathrm{ml}$ of ASW per well in 6-well plates. Two different concentrations were assessed for each inhibitor: AZD2014 $(0.25$ and $0.5 \mu \mathrm{M})$, GSK690693 $(2.5$ and $5 \mu \mathrm{M})$ and tipifarnib (5 and 10 $\mu \mathrm{M})$. Treatment was performed after visible assembly of the sea urchin fertilization membrane, which occurs approximately $20 \mathrm{~min}$ after sperm fusion with the egg. After $24 \mathrm{~h}$, control and treated embryos were examined under Leica DMI4000 B microscope (Leica Microsystems GmbH, Germany) at $5 \times$ magnification. A minimum of 30 embryos were observed for each condition. The results are presented as percentage of nonviable and viable embryos in different developmental stages (undeveloped embryos, swimming blastula and late gastrula) in control and treated groups.

\section{Statistical analysis}

All data are shown as mean \pm SEM. Differences between control and single treatments were assessed using one-way analysis of variance (ANOVA) followed by Dunette's test. In combined treatments, the results were analyzed with $t$-test. The minimum significant level was set at $p \leq 0.05$. Statistical analyses were performed using GraphPad Prism 5 or 6.

\section{RESULTS}

\section{Wortmannin causes decreased embryo survival and morphological malformations}

There were no significant differences between untreated embryos and embryos incubated in $0.01 \%$ DMSO. Untreated embryos did not show mortality or developmental malformations at any time of observation. Hatching rate of untreated embryos was around $44 \%$ at $48 \mathrm{hpf}$ and $100 \%$ at $72 \mathrm{hpf}$.

Wortmannin induced dose-dependent decreased survival rate in embryos treated 2 and $6 \mathrm{hpf}$ when compared to the control group at $72 \mathrm{hpf}$. However, only $2.5 \mu \mathrm{M}$ treatment applied at $2 \mathrm{hpf}$ produced a statistically significant result (58\%, Fig. 1A). Wortmannin also induced a dose- dependent hatching rate decrease in embryos treated 2 and 6 hpf when compared to the control group at 48 hpf (Fig. 1B). Still, only $2.5 \mu \mathrm{M}$ treatment applied at $2 \mathrm{hpf}$ caused statistically significant result by completely blocking the hatching. 
Table 1

Embryo malformations induced by wortmannin

\begin{tabular}{|l|c|c|c|c|c|c|c|c|c|}
\hline \multirow{2}{*}{ Malformations } & \multicolumn{3}{|c|}{$2 \mathrm{hpf}$} & \multicolumn{3}{c|}{$6 \mathrm{hpf}$} & \multicolumn{3}{c|}{$24 \mathrm{hpf}$} \\
\cline { 2 - 11 } & $0.5 \mu \mathrm{M}$ & $1 \mu \mathrm{M}$ & $2.5 \mu \mathrm{M}$ & $0.5 \mu \mathrm{M}$ & $1 \mu \mathrm{M}$ & $2.5 \mu \mathrm{M}$ & $0.5 \mu \mathrm{M}$ & $1 \mu \mathrm{M}$ & $2.5 \mu \mathrm{M}$ \\
\hline $\begin{array}{l}\text { Decreased body } \\
\text { length }\end{array}$ & $\mathrm{np}$ & $100 \%$ & $100 \%$ & $\mathrm{np}$ & $100 \%$ & $100 \%$ & $\mathrm{np}$ & $100 \%$ & $100 \%$ \\
\hline Voluminous yolk sac & $\mathrm{np}$ & $100 \%$ & $\mathrm{np}$ & $\mathrm{np}$ & $100 \%$ & $\mathrm{np}$ & $\mathrm{np}$ & $100 \%$ & $\mathrm{np}$ \\
\hline Yolk sac edema & $\mathrm{np}$ & $\mathrm{np}$ & $100 \%$ & $\mathrm{np}$ & $\mathrm{np}$ & $100 \%$ & $\mathrm{np}$ & $\mathrm{np}$ & $100 \%$ \\
\hline Pericardial edema & $\mathrm{np}$ & $\mathrm{np}$ & $100 \%$ & $\mathrm{np}$ & $\mathrm{np}$ & $100 \%$ & $\mathrm{np}$ & $52 \%$ & $100 \%$ \\
\hline Scoliosis & $\mathrm{np}$ & $\mathrm{np}$ & $22 \%$ & $\mathrm{np}$ & $\mathrm{np}$ & $\mathrm{np}$ & $\mathrm{np}$ & $\mathrm{np}$ & $\mathrm{np}$ \\
\hline
\end{tabular}

*np - not present.

A

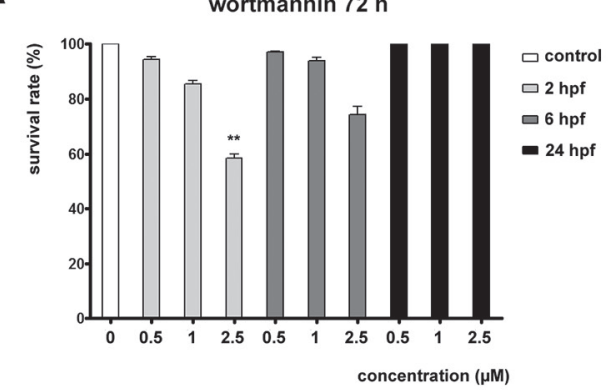

B

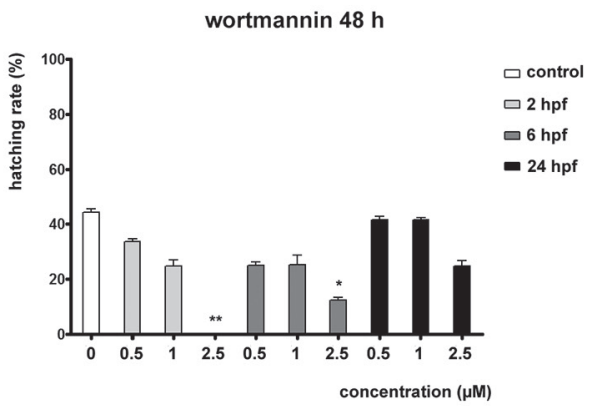

C

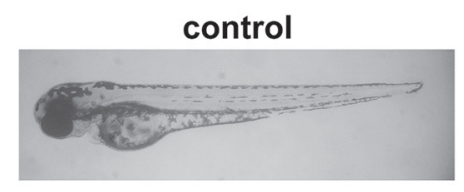

wortmannin $2 \mathrm{hpf}$

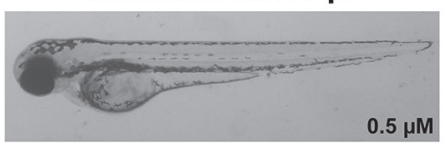

$0.5 \mu \mathrm{M}$
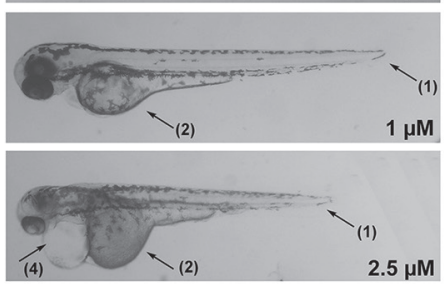
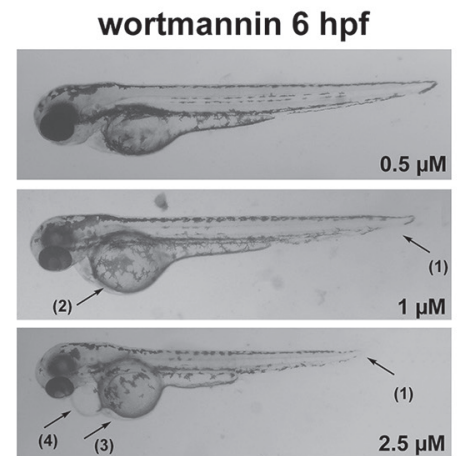
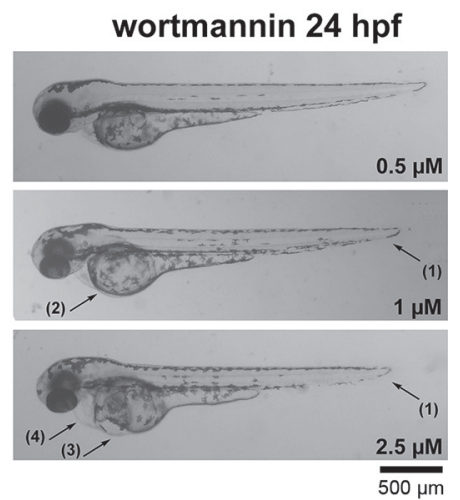

Fig. 1. Wortmannin affects survival and development in zebrafish embryos. A) Survival rate of $72 \mathrm{hpf}$ zebrafish embryos treated with wortmannin at 2, 6 or $24 \mathrm{hpf}$. B) Hatching rate of $48 \mathrm{hpf}$ zebrafish embryos treated with wortmannin at 2, 6 or $24 \mathrm{hpf}$. C) Representative images of morphological malformations in $72 \mathrm{hpf}$ zebrafish embryos treated with wortmannin at 2,6 or $24 \mathrm{hpf}$ 
Wortmannin treatment induced multiple malformations in zebrafish embryos. The observed effects were more prominent in earlier treatment starting points and were concentration dependent (Table 1, Fig. 1C). Treatment with $1 \mu \mathrm{M}$ wortmannin decreased body length and produced voluminous yolk sac in comparison to the control group. Furthermore, embryos treated with $1 \mu \mathrm{M}$ wortmannin $24 \mathrm{hpf}$ had pericardial edema. Treatment with $2.5 \mu \mathrm{M}$ wortmannin caused shorter body length compared to controls and $0.5 \mu \mathrm{M}$ and $1 \mu \mathrm{M}$ treatments, as well as yolk sac edema and pericardial edema. Additionally, embryos treated with $2.5 \mu \mathrm{M}$ wortmannin $2 \mathrm{hpf}$ showed scoliosis (Table 1, Fig. 1C).

\section{GSK690693 and AZD2014 do not influence zebrafish embryo survival and development}

The zebrafish embryos were also treated at different time points with increasing concentrations of GSK690693. GSK690693 did not affect survival or embryonic development, but decreased hatching of the embryos observed at $48 \mathrm{hpf}$ in comparison to

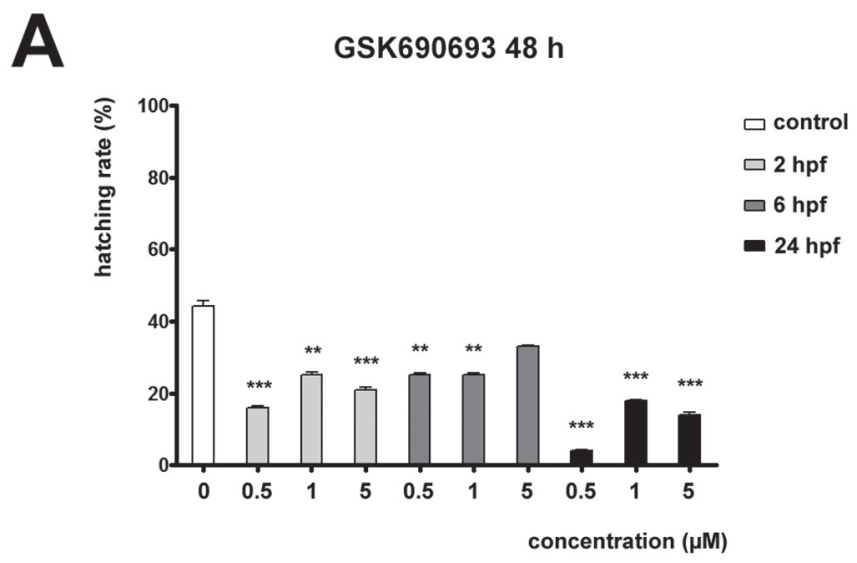

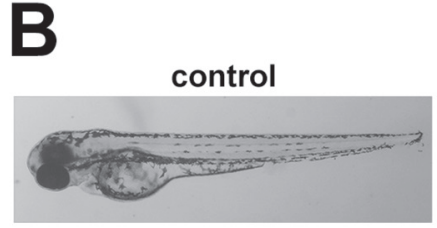

GSK690693 6 hpf

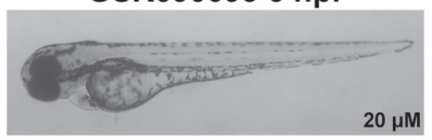

GSK690693 2 hpf

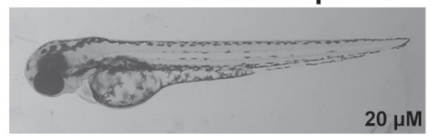

GSK690693 24 hpf

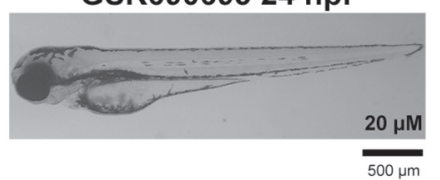

Fig. 2. GSK690693 affects hatching but not development in zebrafish embryos. A) Hatching rate of 48 hpf zebrafish embryos treated with GSK690693 at 2, 6 or 24 hpf. B) Representative images of 72 hpf zebrafish embryos treated with GSK690693 at 2, 6 or $24 \mathrm{hpf}$ 
control groups. All concentrations of GSK690693 decreased hatching rate of embryos at all treatment starting time points (Fig. 2A). No malformations during the development were observed in any of the GSK690693 treatments (Fig. 2B). Treatment with increasing concentrations of AZD2014 caused dose-dependent decrease in hatching rate at all treatment starting time points (Fig. 3A). No differences in survival of AZD2014 treated embryos compared to controls, or any malformations during the development were observed (Fig. 3B).

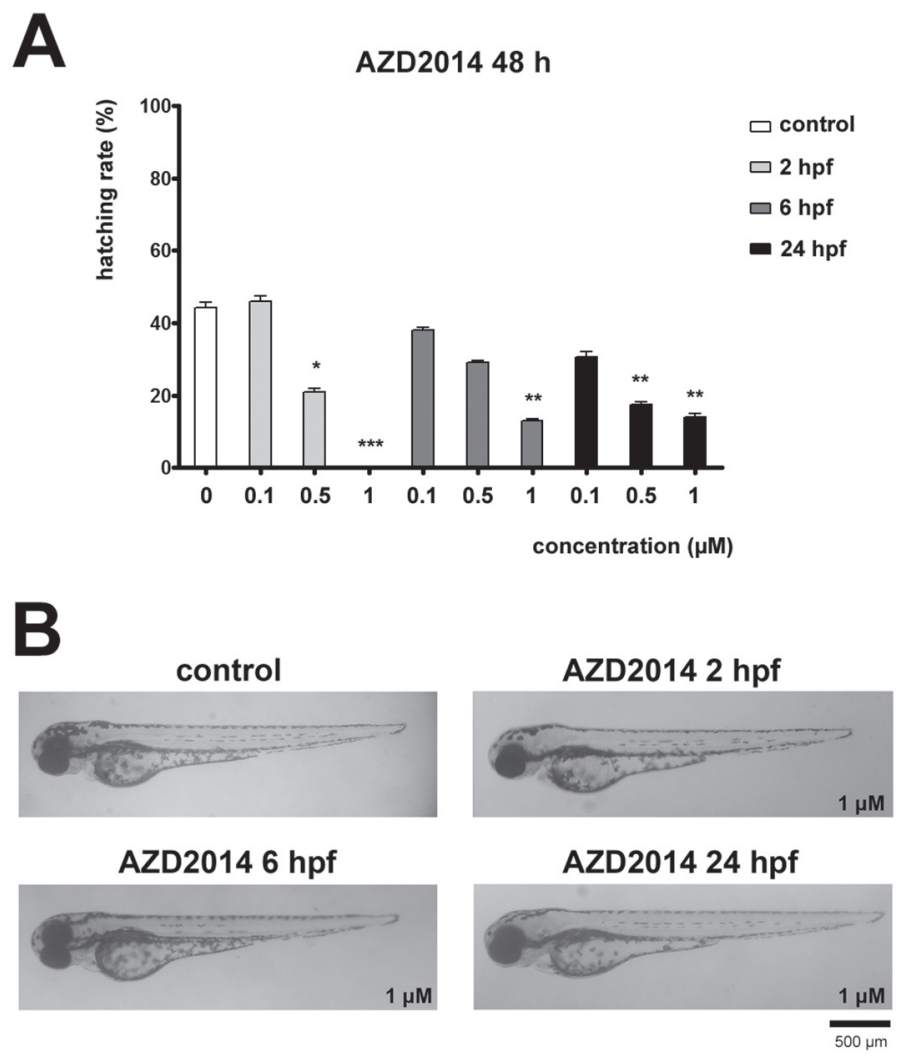

Fig. 3. AZD2014 affects hatching but not development in zebrafish embryos. A) Hatching rate of $48 \mathrm{hpf}$ zebrafish embryos treated with AZD2014 at 2, 6 or 24 hpf. B) Representative images of $72 \mathrm{hpf}$ zebrafish embryos treated with AZD2014 at 2, 6 or $24 \mathrm{hpf}$

\section{Co-treatments with PI3K-Akt-mTOR pathway inhibitors cause decrease in zebrafish embryo survival and multiple malformations}

Subsequently, the embryos were exposed to combined treatment with wortmannin and GSK690693 or GSK690693 and AZD2014. Combined treatment with $1 \mu \mathrm{M}$ wortmannin and $1 \mu \mathrm{M}$ GSK690693 significantly decreased embryo survival rate 


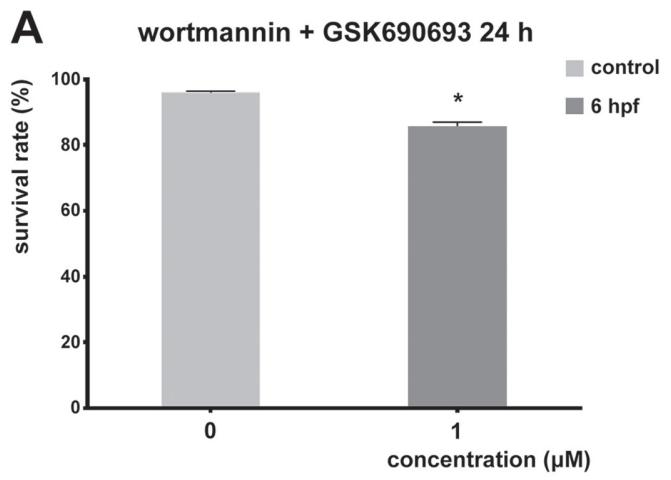

\section{B wortmannin + GSK690693}
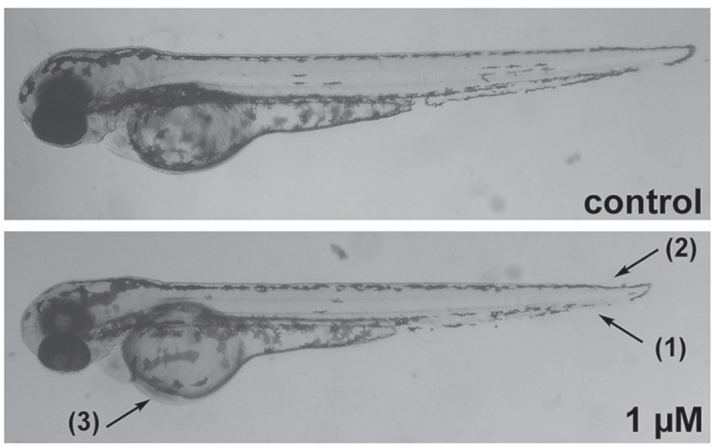

\section{GSK690693 + AZD2014}

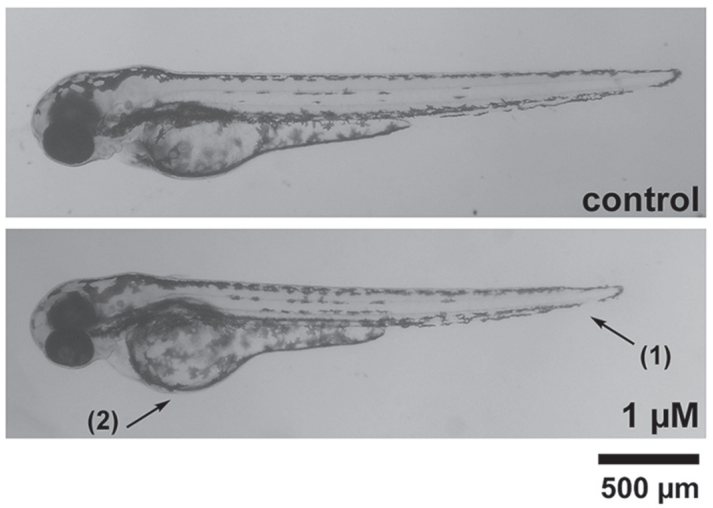

Fig. 4. PI3K-Akt-mTOR pathway inhibitors co-treatments affect survival and development in zebrafish embryos. A) Survival rate of 24 hpf zebrafish embryos treated with wortmannin and GSK690693 combination at $6 \mathrm{hpf}$. B) Representative images of morphological malformations in $72 \mathrm{hpf}$ zebrafish embryos treated with wortmannin and GSK690693 combination at $6 \mathrm{hpf}$. C) Representative images of morphological malformations in $72 \mathrm{hpf}$ zebrafish embryos treated with GSK690693 and AZD2014 combination at $6 \mathrm{hpf}$ 
(86\%) observed at $24 \mathrm{hpf}$ (Fig. 4A). Additionally, all embryos had decreased body length, while $79 \%$ of embryos had hemagglutination and $70 \%$ had malformation of the tail (Fig. 4B).

Combined treatment with $1 \mu \mathrm{M}$ GSK690693 and $1 \mu \mathrm{M}$ AZD2014 inhibitors did not alter survival or hatching rate, however decreased body length of all embryos was observed. Additionally, this combined treatment caused voluminous yolk sac in $65 \%$ of treated embryos (Fig. 4C).

\section{Tipifarnib causes multiple morphological malformations in zebrafish embryos}

Tipifarnib treatment did not affect the embryo survival or hatching rate, however, multiple malformations of the embryos were observed all treatment starting time points (Fig. 5). The most prominent malformation was decrease in body length (Table 2). Yolk sac edema and pericardial edema were also observed.

Table 2

Embryo malformations induced by tipifarnib

\begin{tabular}{|l|c|c|c|c|c|c|c|c|c|}
\hline \multirow{2}{*}{ Malformations } & \multicolumn{4}{|c|}{$2 \mathrm{hpf}$} & \multicolumn{3}{c|}{$6 \mathrm{hpf}$} & \multicolumn{3}{c|}{$24 \mathrm{hpf}$} \\
\cline { 2 - 12 } & $1 \mu \mathrm{M}$ & $5 \mu \mathrm{M}$ & $10 \mu \mathrm{M}$ & $1 \mu \mathrm{M}$ & $5 \mu \mathrm{M}$ & $10 \mu \mathrm{M}$ & $1 \mu \mathrm{M}$ & $5 \mu \mathrm{M}$ & $10 \mu \mathrm{M}$ \\
\hline Decreased body length & $\mathrm{np}$ & $100 \%$ & $100 \%$ & $\mathrm{np}$ & $100 \%$ & $100 \%$ & $\mathrm{np}$ & $\mathrm{np}$ & $100 \%$ \\
\hline Voluminous yolk sac & $\mathrm{np}$ & $65 \%$ & $100 \%$ & $\mathrm{np}$ & $\mathrm{np}$ & $100 \%$ & $\mathrm{np}$ & $\mathrm{np}$ & $82 \%$ \\
\hline Pericardial edema & $\mathrm{np}$ & $\mathrm{np}$ & $27 \%$ & $\mathrm{np}$ & $\mathrm{np}$ & $36 \%$ & $\mathrm{np}$ & $\mathrm{np}$ & $\mathrm{np}$ \\
\hline
\end{tabular}

*np - not present.

\section{The effects of PI3K-Akt-mTOR and RAS-MAPK-ERK pathway inhibitors on early sea urchin development}

Fertilized sea urchin eggs were treated with $0.25 \mu \mathrm{M}$ or $0.5 \mu \mathrm{M}$ AZD2014 $20 \mathrm{~min}$ after fertilization and the effect on the embryo survival and development was observed after $24 \mathrm{~h}$ (Fig. 6). Treatment with $0.25 \mu \mathrm{M}$ produced $8 \%$ late gastrula embryos while $52 \%$ of embryos were dead after $24 \mathrm{~h}$. The mobility of live embryos was reduced compared to the untreated group. After treatment with $0.5 \mu \mathrm{M}$ AZD2014 $2 \%$ of embryos reached the late gastrula stage, $3 \%$ of embryos were arrested as deformed stationary blastulas (compared to $23 \%$ swimming blastulas in the control group) and $74 \%$ of embryos became nonviable.

After $24 \mathrm{~h}$ treatment with $2.5 \mu \mathrm{M}$ GSK690693 there were no late gastrulas and 4\% embryos were arrested at the swimming blastula stage which retained mobility despite their altered morphology (Fig. 6). However, the majority of embryos remained undeveloped (57\% in treated group compared to $15 \%$ in control) and $39 \%$ of embryos were dead. Treatment with $5 \mu$ M GSK690693 produced 63\% undeveloped 


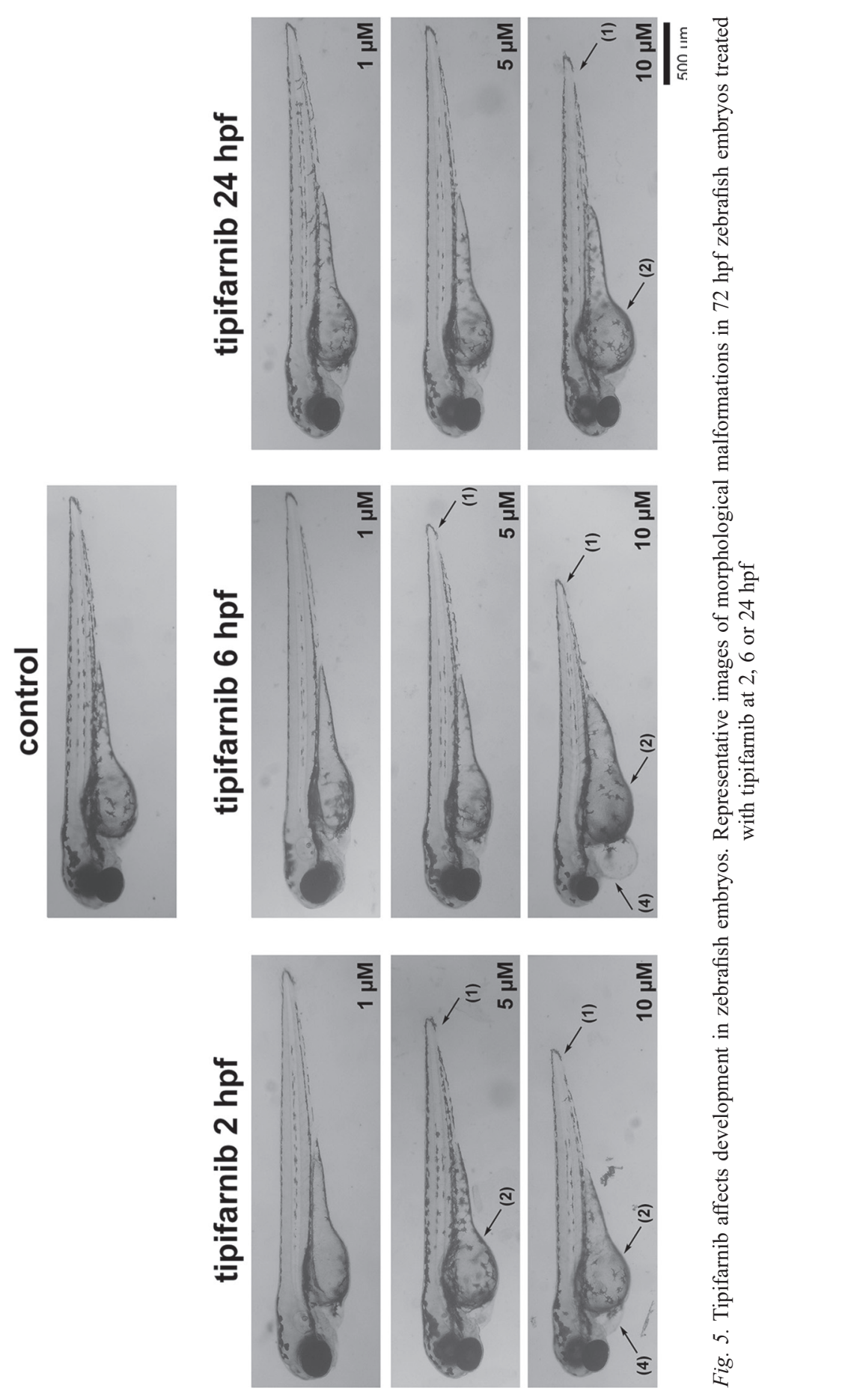

Acta Biologica Hungarica 69, 2018 

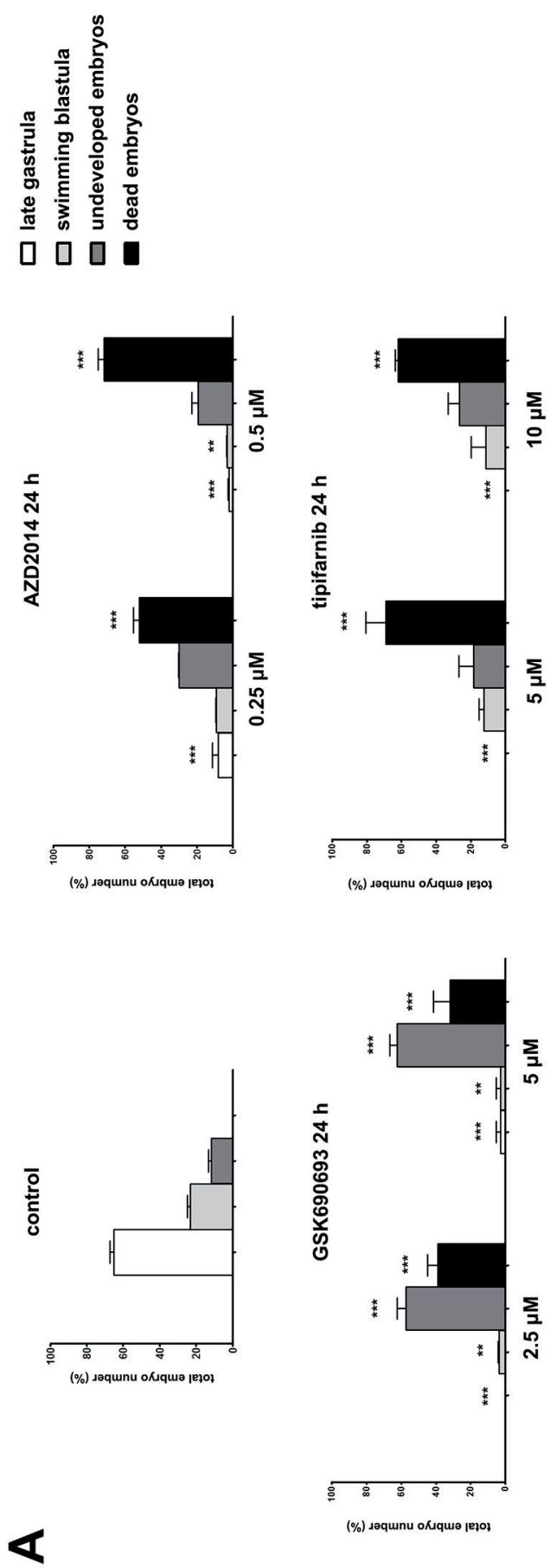

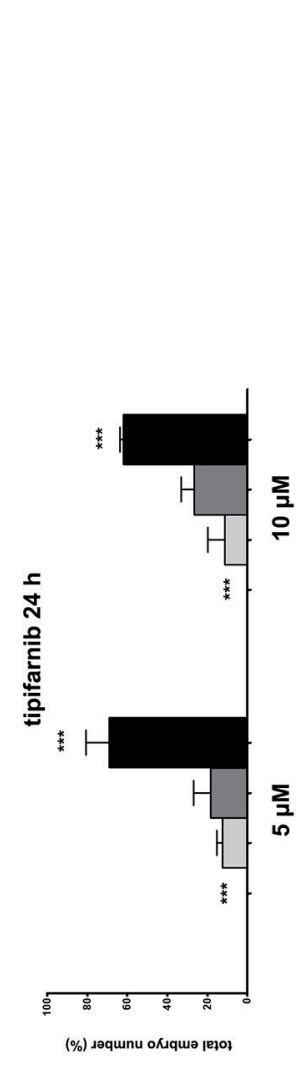

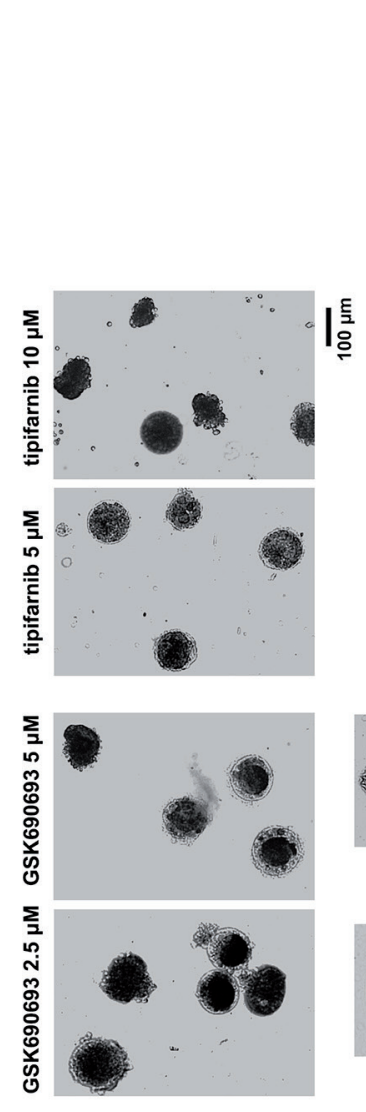
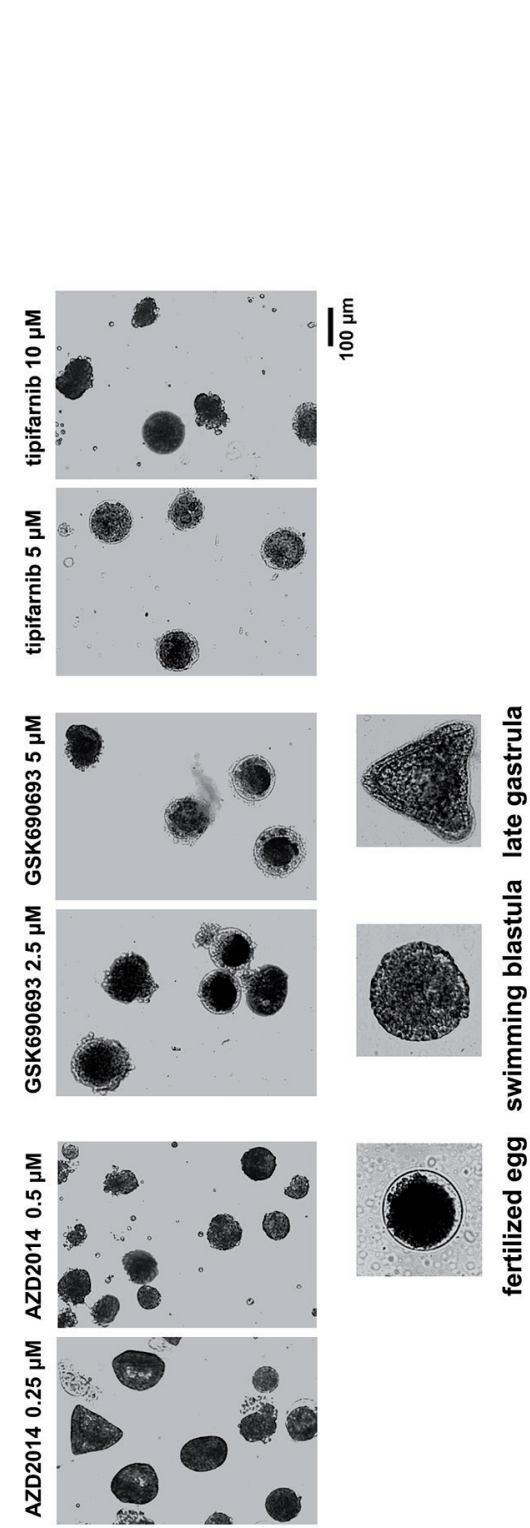

总奉

苛离

흥.

要

४

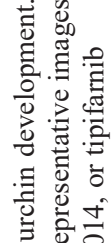

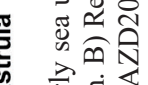

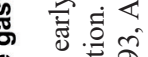

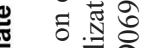

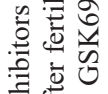

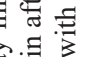
烈

贾, 它

色

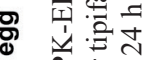

总 茫芯 is 술

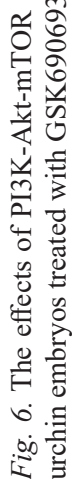


embryos, $3 \%$ of swimming blastulas with significantly reduced mobility and $32 \%$ of dead embryos. The morphology of undeveloped embryos was significantly altered.

After the fertilization membrane became visible, sea urchin embryos were also treated with $5 \mu \mathrm{M}$ or $10 \mu \mathrm{M}$ tipifarnib (Fig. 6). The impact on embryo viability and developmental delay was observed after $24 \mathrm{~h}$. Treatment with $5 \mu \mathrm{M}$ tipifarnib arrested the embryos at various stages of development. Compared to control where $62 \%$ of embryos reached the late gastrula, none of the embryos treated with $5 \mu \mathrm{M}$ tipifarnib were observed at this developmental stage. Furthermore, the treatment had a high impact on viability since $69 \%$ of embryos became nonviable after $24 \mathrm{~h}$ while no dead embryos were found in the control group. Application of higher concentration of tipifarnib $(10 \mu \mathrm{M})$ produced similar results.

\section{DISCUSSION}

One of the currently most investigated problems in cancer treatment is the development of non-toxic therapies to normal cells,mean while retaining the ability to successfully inhibit tumor growth. Novel adjuvant therapies are being developed to increase the effectiveness of existing drugs.

This study was addressed to the time- and dose-dependent responses of zebrafish and dose-dependent responses of sea urchin embryos on chemical inhibitors of PI3K-Akt-mTOR and RAS-MAPK-ERK signaling pathways components. The toxic effects of these inhibitors alone or in combinations were investigated in vivo in zebrafish and sea urchin embryos that served as models for fast proliferating, but not transformed cells. To the best of our knowledge, this is the first report investigating the effects of GSK690693, AZD2014 and tipifarnib on zebrafish and sea urchin embryo models.

We have selected several treatment time points for zebrafish embryos: blastula (2 hpf), gastrula (6 hpf) and pharyngula (24 hpf) stages, as numerous differences in speed and pattern of cell proliferation during these developmental stages have previously been reported [25]. The most prominent effects on the embryo survival and development were present in treatments started at the earliest time point in all studied inhibitors. Inhibitor concentrations selected for treatments were previously shown to have a significant effect on proliferation, and trigger autophagy and apoptosis in normal and cancer cell lines [10]. It should be taken into account that, compared to zebrafish embryos, sea urchin embryos were found to be generally more sensitive to a number of chemicals and drugs [6], which is in line with our observations.

Wortmannin, a PI3K inhibitor, has been previously shown to exhibit high toxicity during fertilization and development of sea urchin [9]. It has been reported that wortmannin treatment disrupts the mitotic spindle formation and subsequently the first cell division of the fertilized egg. Similarly, in our model wortmannin treatment resulted only in nonviable disintegrated embryos after 24 hours and was therefore excluded from our sea urchin experiments. In zebrafish embryos, treatment with 2.5 $\mu \mathrm{M}$ wortmannin at the blastula stage decreased embryo survival and hatching rate. 
Additionally, several morphological malformations have also been observed. It has been previously shown that wortmannin exhibited high cardiotoxicity in zebrafish embryos although independently of PI3K inhibition [32]. It has also been reported that wortmannin affected cancer cell growth at micromolar concentrations $\left(\mathrm{IC}_{50}=30\right.$ $\mu \mathrm{M})$ and improved the activity of doxorubicin and cisplatin in thyroid carcinoma cell lines [27]. Our observation, that wortmannin exhibits substantial effects on zebrafish survival and morphology in much lower concentrations compared to human cancer cell lines $(2.5 \mu \mathrm{M})$, does not favor this inhibitor as an anticancer agent as it affects normal as well as cancer cells.

GSK690693 is a small molecule that acts as ATP-competitive inhibitor of Akt1, Akt 2 and Akt3. This agent affected sea urchin fertilization and development, but its effects on zebrafish development were negligible. It did not impact zebrafish embryo survival, but caused delayed hatching that could not be attributed to either the time of treatment or applied concentration. The process of hatching is complex and influenced by many physical and chemical factors. In zebrafish, hatching glands produce proteolytic enzyme that weakens chorion and facilitates hatching [8]. Also, oxygenation of water and other physic-chemical water properties could affect hatching [15]. Presence of pollutants in water has been shown to influence hatching rate [31]. As the differences between treated animals and controls in hatching rate were not present after $72 \mathrm{hpf}$ (all the surviving embryos were hatched in all groups), the detailed analysis of hatching was not performed. GSK690693 has been found to be active in vitro against many cell types, inhibiting their growth in micro molar range $\left(\mathrm{IC}_{50}\right.$ values from 8 to $25 \mu \mathrm{M})$ [7, 21, 27]. However, in vivo studies on xenograft models, GSK690693 exhibited effects not very promising to further promote it as anticancer agent $[2,7]$.

AZD2014 is an ATP-competitive mTOR kinase inhibitor, affecting both mTORC1 and mTORC2, currently in phase II clinical trials [13]. In our experimental setup, AZD2014 treatment did not affect embryo survival, but resulted in time- and dosedependent delayed hatching at $48 \mathrm{hpf}$, compared to controls, but this difference disappeared after 72 hpf. AZD2014 treatment leads to body length shortening in some embryos only at highest, $1 \mu \mathrm{M}$, concentration.

None of the AZD2014 treated embryos showed any other morphological malformations. Although sea urchin embryo viability was low and substantial developmental delay was observed in all treatments, only treatment with AZD2014 managed to produce a noteworthy number of embryos that reached the swimming blastula and late gastrula stage. It has been shown that AZD2014 sensitized oral squamous cancer cells and glioblastoma stem-like cells to treatment with ionizing radiation [19, 33]. In vitro, AZD2014 showed highest growth arrest potential in thyroid and colorectal cancer cells, acting in nanomolar range ( $\mathrm{IC}_{50}$ values from 0.15 to $\left.0.21 \mu \mathrm{M}\right)$, compared to the other inhibitors used in this study $[18,27]$. Additionally, it was demonstrated that it most effectively lowered $\mathrm{IC}_{50}$ values for classic chemotherapeutics doxorubicin and paclitaxel [27]. AZD2014 was also shown to inhibit proliferation and induce apoptosis in liver cancer cells [22]. In our previous work, we have found that AZD2014 induced autophagy in concentrations that had no effect on development, 
and prevented cisplatin-induced apoptosis in zebrafish embryos. Autophagy modulation with AZD2014 triggered the cellular response to anticancer drugs more effectively in NCI-H460 (human non-small cell lung carcinoma) and zebrafish embryonic models compared to human normal $\mathrm{HaCaT}$ cells suggesting that these modulators are selective towards rapidly proliferating cells [10]. Taken together with these findings, our results further promote AZD2014 as a promising anticancer agent. Of all the inhibitors tested, AZD2014 had the least influence on the normal embryonic development.

Wortmannin and GSK690693 combination treatment significantly decreased zebrafish embryo survival after $72 \mathrm{~h}$ at even lower wortmannin concentration implying a synergistic action of the two PI3K/Akt/mTOR inhibitors. Combined treatment with inhibitors of downstream part of the PI3K/Akt/mTOR pathway, GSK690693 and AZD2014, did not significantly affect the survival of the treated embryos. Wortmannin + GSK690693 and GSK690693 +AZD2014 co-treatments produced morphological malformations not present in single treatments (hemagglutination and yolk sac malformation) which further implies the synergistic action between these inhibitors.

Tipifrnib is a Ras pathway inhibitor approved by USFDA for the treatment of elderly acute leukemia, and is in phase II clinical trials for several other types of cancer [3]. In our study, treatment with tipifarnib affected zebrafish embryo morphology as well as survival and development of sea urchin embryos, displaying higher toxicity on normal embryonic cells, compared to AZD2014 and GSK690693. Tipifarnib has been shown to effectively arrests cell growth in micro molar concentrations $\left(\mathrm{IC}_{50}\right.$ values ranging from 2 to $\left.8 \mu \mathrm{M}\right)$ [27]. Meanwhile it was very toxic to sea urchin embryos and caused zebrafish embryo malformations, we have shown that tipifarnib has prominent effect on normal proliferating cells.

\section{CONCLUSIONS}

In the search for new anticancer drugs, the main focus is placed on finding compounds with substantial capacity to inhibit the cancer cell growth, particularly in resistant cancers, while exhibiting negligible effects on normal cells during the course of chemotherapy. We found that AZD2014 had no major effects on fast proliferating normal cells of zebrafish embryos in concentrations that induced substantial toxicity in cancer cells. Treatment with AZD2014 also caused the least prominent effects on sea urchin embryo development compared to other investigated inhibitors which target signaling pathways involved in regulating cell survival and proliferation.

Although further investigations are needed, the significant toxicity of AZD2014 in human cancer cells, its capacity to sensitize resistant cancers, lower antiproliferative activity against human normal cell lines as well as fast proliferating embryonic cells could make this agent a promising candidate for anticancer therapy. 


\section{ACKNOWLEDGMENTS}

This work has been supported by Ministry of Education, Science and Technological Development of Serbia (Grant Nos. ON173008 and III41031).

\section{REFERENCES}

1. Ahronian, L. G., Corcoran, R. B. (2017) Strategies for monitoring and combating resistance to combination kinase inhibitors for cancer therapy. Genome Med. 9, 37.

2. Altomare, D. A., Zhang, L., Deng, J., Di Cristofano, A., Klein-Szanto, A. J., Kumar, R. (2010) GSK690693 delays tumor onset and progression in genetically defined mouse models expressing activated Akt. Clin. Cancer Res. 16, 486-496.

3. Asati, V., Mahapatra, D. K., Bharti, S. K. (2017) K-Ras and its inhibitors towards personalized cancer treatment: Pharmacological and structural perspectives. Eur. J. Med. Chem. 125, 299-314.

4. Berghmans, S., Jette, C., Langenau, D., Hsu, K., Stewart, R., Look, T. (2005) Making waves in cancer research: new models in the zebrafish. Biotechniques 39, 227-237.

5. Blagosklonny, M. V. (2004) Analysis of FDA approved anticancer drugs reveals the future of cancer therapy. Cell Cycle 3, 1035-1042.

6. Brausch, J. M., Rand, G. M. (2011) A review of personal care products in the aquatic environment: environmental concentrations and toxicity. Chemosphere 82, 1518-1532.

7. Carol, H., Morton, C. L., Gorlick, R., Kolb, E. A., Keir, S. T., Reynolds, C. P. (2010) Initial testing (stage 1) of the Akt inhibitor GSK690693 by the pediatric preclinical testing program. Pediatr. Blood Cancer. 55, 1329-1337.

8. De la Paz, J. F., Beiza, N., Paredes-Zuniga, S., Hoare, M. S., Allende, M. L. (2017) Triazole Fungicides Inhibit Zebrafish Hatching by Blocking the Secretory Function of Hatching Gland Cells. Int. J. Mol. Sci. 18.

9. De Nadai, C., Huitorel, P., Chiri, S., Ciapa, B. (1998) Effect of wortmannin, an inhibitor of phosphatidylinositol 3-kinase, on the first mitotic divisions of the fertilized sea urchin egg. J. Cell Sci. 111, 2507-2518.

10. Divac Rankov, A., Ljujic, M., Petric, M., Radojkovic, D., Pesic, M., Dinic, J. (2017) Targeting autophagy to modulate cell survival: a comparative analysis in cancer, normal and embryonic cells. Histochem. Cell Biol. 148, 529-544.

11. Eimon, P. M., Rubinstein, A. L. (2009) The use of in vivo zebrafish assays in drug toxicity screening. Expert Opin. Drug Metab. Toxicol. 5, 393-401.

12. Garcia, G. R., Noyes, P. D., Tanguay, R. L. (2016) Advancements in zebrafish applications for 21st century toxicology. Pharmacol. Ther. 161, 11-21.

13. Guichard, S. M., Curwen, J., Bihani, T., D’Cruz, C. M., Yates, J. W., Grondine, M. (2015) AZD2014 an Inhibitor of mTORC1 and mTORC2, Is Highly Effective in ER+ Breast Cancer When Administered Using Intermittent or Continuous Schedules. Mol. Cancer Ther. 14, 2508-2518.

14. He, J. H., Gao, J. M., Huang, C. J., Li, C. Q. (2014) Zebrafish models for assessing developmental and reproductive toxicity. Neurotoxicol. Teratol. 42, 35-42.

15. He, Q., Liu, K., Wang, S., Hou, H., Yuan, Y., Wang, X. (2012) Toxicity induced by emodin on zebrafish embryos. Drug Chem. Toxicol. 35, 149-154.

16. Howe, K., Clark, M. D., Torroja, C. F., Torrance, J., Berthelot, C., Muffato, M. (2013) The zebrafish reference genome sequence and its relationship to the human genome. Nature 496, 498-503.

17. Hung, M. W., Zhang, Z. J., Li, S., Lei, B., Yuan, S., Cui, G. Z. (2012) From omics to drug metabolism and high content screen of natural product in zebrafish: a new model for discovery of neuroactive compound. Evid. Based Complement. Alternat. Med. 2012, 605303.

18. Huo, H. Z., Zhou, Z. Y., Wang, B., Qin, J., Liu, W. Y., Gu, Y. (2014) Dramatic suppression of colorectal cancer cell growth by the dual mTORC1 and mTORC2 inhibitor AZD-2014. Biochem. Biophys. Res. Commun. 443, 406-412. 
19. Kahn, J., Hayman, T. J., Jamal, M., Rath, B. H., Kramp, T., Camphausen, K. (2014) The mTORC1/ mTORC2 inhibitor AZD2014 enhances the radiosensitivity of glioblastoma stem-like cells. Neuro. Oncol. 16, 29-37.

20. Korkina, L. G., Deeva, I. B., De Biase, A., Iaccarino, M., Oral, R., Warnau, M. (2000) Redoxdependent toxicity of diepoxybutane and mitomycin $\mathrm{C}$ in sea urchin embryogenesis. Carcinogenesis $21,213-220$

21. Levy, D. S., Kahana, J. A., Kumar, R. (2009) AKT inhibitor, GSK690693, induces growth inhibition and apoptosis in acute lymphoblastic leukemia cell lines. Blood. 113, 1723-1729.

22. Liao, H., Huang, Y., Guo, B., Liang, B., Liu, X., Ou, H. (2015) Dramatic antitumor effects of the dual mTORC1 and mTORC2 inhibitor AZD2014 in hepatocellular carcinoma. Am. J. Cancer Res. $5,125-139$.

23. Marin, J. J. G., Lozano, E., Herraez, E., Asensio, M., Di Giacomo, S., Romero, M. R. (2018) Chemoresistance and chemosensitization in cholangiocarcinoma. Biochim. Biophys. Acta 1864, 1444-1453.

24. McCubrey, J. A., Steelman, L. S., Abrams, S. L., Lee, J. T., Chang, F., Bertrand, F. E. (2006) Roles of the RAF/MEK/ERK and PI3K/PTEN/AKT pathways in malignant transformation and drug resistance. Adv. Enzyme Regul. 46, 249-279.

25. Mendieta-Serrano, M. A., Schnabel, D., Lomeli, H., Salas-Vidal, E. (2013) Cell proliferation patterns in early zebrafish development. Anat. Rec. (Hoboken). 296, 759-773.

26. Mendoza, M. C., Er, E. E., Blenis, J. (2011) The Ras-ERK and PI3K-mTOR pathways: cross-talk and compensation. Trends Biochem. Sci. 36, 320-328.

27. Milosevic, Z., Pesic, M., Stankovic, T., Dinic, J., Milovanovic, Z., Stojsic, J. (2014) Targeting RASMAPK-ERK and PI3K-AKT-mTOR signal transduction pathways to chemosensitize anaplastic thyroid carcinoma. Transl. Res. 164, 411-423.

28. Nishioka, D., Marcell, V., Cunningham, M., Khan, M., Von Hoff, D. D., Izbicka, E. (2003) The use of early sea urchin embryos in anticancer drug testing. Methods Mol. Med. 85, 265-276.

29. Samatar, A. A., Poulikakos, P. I. (2014) Targeting RAS-ERK signalling in cancer: promises and challenges. Nat. Rev. Drug Discov. 13, 928-942.

30. Sconzo, G., Romancino, D., Fasulo, G., Cascino, D., Giudice, G. (1995) Effect of doxorubicin and phenytoin on sea urchin development. Pharmazie 50, 616-619.

31. Torres, T., Cunha, I., Martins, R., Santos, M. M. (2016) Screening the Toxicity of Selected Personal Care Products Using Embryo Bioassays: 4-MBC, Propylparaben and Triclocarban. Int. J. Mol. Sci. 17.

32. Wang, Y., Zhong, T., Qian, L., Dong, Y., Jiang, Q., Tan, L. (2005) Wortmannin induces zebrafish cardia bifida through a mechanism independent of phosphoinositide 3-kinase and myosin light chain kinase. Biochem. Biophys. Res. Commun. 331, 303-308.

33. Yu, C. C., Huang, H. B., Hung, S. K., Liao, H. F., Lee, C. C., Lin, H. Y. (2016) AZD2014 Radiosensitizes Oral Squamous Cell Carcinoma by Inhibiting AKT/mTOR Axis and Inducing G1/ G2/M Cell Cycle Arrest. PLoS One. 11, e0151942. 